\title{
Accident Detection by an Intelligent System
}

\author{
Bhalerao Harshal A. ${ }^{1}$, Jadhav Sarika $\mathbf{J}^{2}$, Jadhav Snehal B ${ }^{3}$ \\ Student, Computer Engineering, Amrutvahini College of Engineering, Sangamner, India ${ }^{1,2,3}$
}

\begin{abstract}
Most of the accidents on highways as well as on roads can lead to social as well as economic impacts. For minor accidents it is not necessary to give much more attention because passengers themselves take care. Whereas other accidents in which airbags are deployed requires immediate attention. Accident Detection by an Intelligent System (ADIS) is a smart system which informs to the emergency contacts through text messages when there is a change in acceleration, rotation and force which is detected by different sensors. These sensors are connected to the central system of the car. The idea behind this system is to inform authorities after collision immediately to avoid congestion and allows passengers to be hospitalized quickly. The system consists of Fuzzy logic as a decision support which decides accident is happened or not.
\end{abstract}

Keywords: Fuzzy Logic, Accident, Arduino, Accelerometer.

\section{INTRODUCTION}

As per results of World Health Organization, approximately 3000 people die in road accidents every year while millions are injured or disabled each year [1]. In many countries, motor vehicle accidents rank first among all fatal accidents. Every year almost 1.3 million people die of road accidents in the world [2].

In India in 2013 as a result of accidents overall 137423 fatalities occurred [3]. The OnStar Corporation is subdivision of General Motors started a service of accident notification. It has an option as Crash Response, Stolen vehicle tracking and Road assistantship. But as per online reviews about system is it cost too much. In contrast ADIS provides only one service detection and notify to the authorised persons. e-NOTIFY is a system that allows fast detection of traffic accidents, improving the assistance of injured passengers by reducing the response time of emergency services and the submission of relevant information on the conditions of the accident using a combination of V2V and V2I communications [4]. It uses the GPS connection of a vehicle to transmit the data, through Internet connection provided by the roadside units, to the service centre that can respond immediately [4].

ADIS functions as a detection and notification service that can be installed in a vehicle and in case of accident detection, requires the microcontroller to send a text message to the response team. The detection of an accident is based on Mamdani fuzzy logic that evaluates, using four parameters (force, acceleration, rotation and speed) to calculate a collision index and if the threshold of the index is met, the microcontroller issues and sends a notification text message. This eliminates the need of the passing by drivers or bystanders to notify the police of the accident.

\section{ADIS SYSTEM DESIGN}

Figure 1 shows an overview of the proposed ADIS system. The accelerometer, gyroscope and force sensor measures the behaviour of the car and inputs the data to the embedded processor where the signals are processed. The fuzzy logic decision support programmed in the controller receives the processed data and makes a decision of detection or no detection. At detection, the microcontroller, through the GSM data network, sends a text message to the emergency contact/public safety.

\section{A. Input Module}

The Input Module reads sensor data on acceleration, rotation and force and passes the collected data to the Embedded Processor. The components of the software architecture are described briefly here:

- $\quad$ Accelerometer: This 3-axial component acquires the data about the current acceleration of the car along three orthogonal axes. The accelerometer is also used to calculate the speed of the vehicle that is used in the fuzzy logic decision support component. As shown in figure 1 Accelerometer is used to check the acceleration.

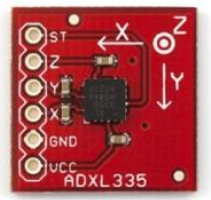

Fig. 1. ADXL 335 Accelerometer 
- Gyroscope: The Gyroscope senses the rotation/tilt of the car and reads the data after processing in degrees per second. This rate of rotation is used for evaluating if the car has rotated to its side or flipped completely.

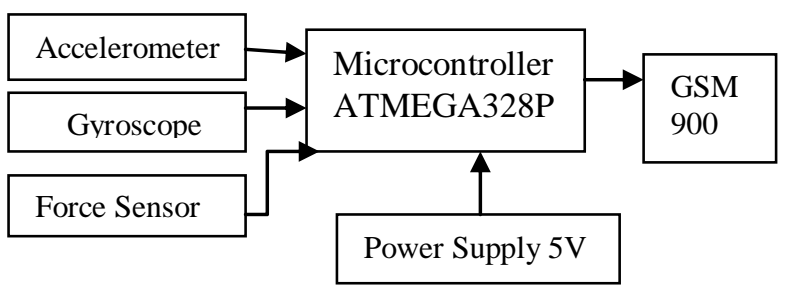

Fig. 2. Proposed System

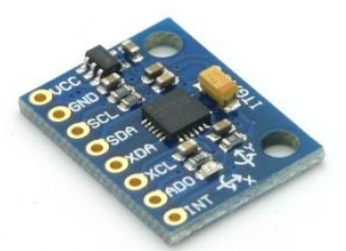

Fig. 3. MPU6050 Gyroscope

- Force Sensor: The four force sensors located at each side of the car detect the impact force of the accident.

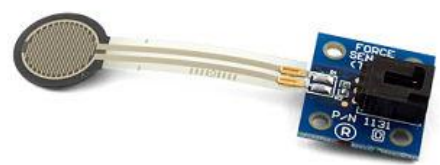

Fig. 4 Force Sensor

B. Microcontroller ATMEGA328P

The Microcontroller plays the role of a translator. It includes a signal-processing module that samples the calibrated data every second, and a GSM module that sends the calibrated data to the emergency contacts. In addition, using the readings of the accelerometer, the speed of the vehicle is calculated.

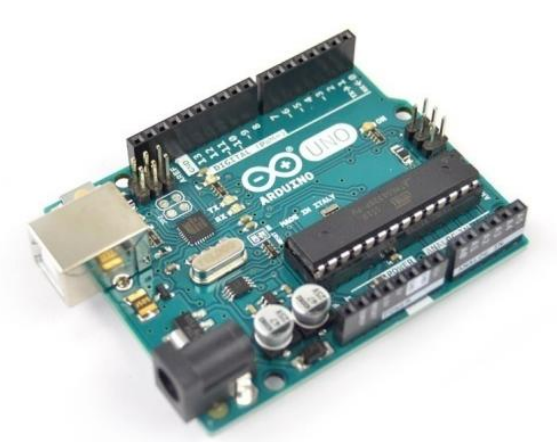

Fig. 5 Microcontroller Board

The Arduino Uno is a microcontroller board based on the ATmega328. Arduino is an open-source, prototyping platform and its simplicity makes it ideal for hobbyists to use as well as professionals. The Arduino Uno has 14 digital input/output pins (of which 6 can be used as PWM outputs), 6 analog inputs, a $16 \mathrm{MHz}$ crystal oscillator, a USB connection, a power jack, an ICSP header, and a reset button. It contains everything needed to support the microcontroller; simply connect it to a computer with a USB cable or power it with a AC-to-DC adapter or battery to get started.

Features of the Arduino UNO:

- Microcontroller: ATmega328

- Operating Voltage: $5 \mathrm{~V}$

- Input Voltage (recommended): 7-12V 
- Input Voltage (limits): 6-20V

- Digital I/O Pins: 14 (of which 6 provide PWM output)

- Analog Input Pins: 6

- DC Current per I/O Pin: $40 \mathrm{~mA}$

- DC Current for 3.3V Pin: $50 \mathrm{~mA}$

- Flash Memory: $32 \mathrm{~KB}$ of which $0.5 \mathrm{~KB}$ used by boot loader

- SRAM: 2 KB (ATmega328)

- EEPROM: $1 \mathrm{~KB}$ (ATmega328)

- Clock Speed: $16 \mathrm{MHz}$

C. GSM 900 Module

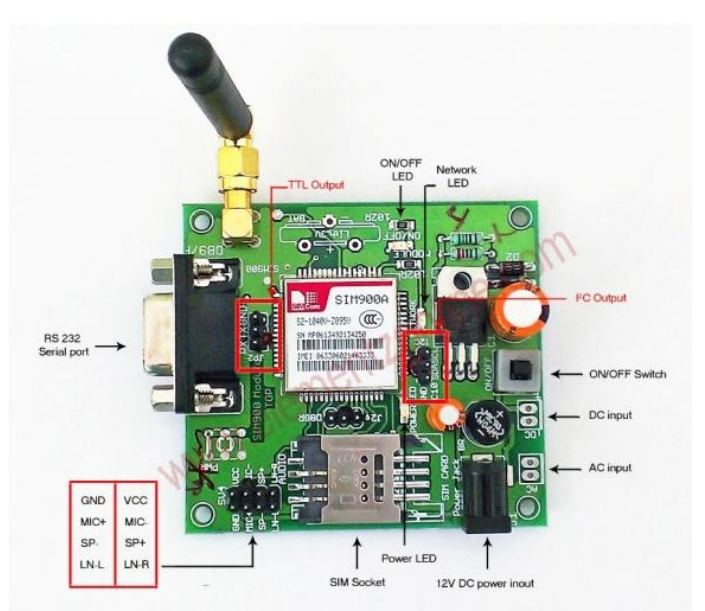

Fig. 6. GSM 900 Module

- Quad-Band 850/ 900/ 1800/ $1900 \mathrm{MHz}$

- Dual-Band 900/ $1900 \mathrm{MHz}$

- GPRS multi-slot class 10/8GPRS mobile station class B

- Compliant to GSM phase 2/2+Class 4 (2 W @ 850/ 900 MHz)

- Class 1(1 W @ 1800/1900MHz)

- Control via AT commands (GSM $07.07,07.05$ and SIMCOM enhanced AT Commands)

- Low power consumption: $1.5 \mathrm{~mA}$ (sleep mode)

- Operation temperature: $-40^{\circ} \mathrm{C}$ to $+85^{\circ} \mathrm{C}$

D. Fuzzy Logic Decision Making

The fuzzy logic decision support is part of the microcontroller which is responsible for evaluating whether an accident has occurred or not. Instead of using fixed threshold values, fuzzy logic uses statistical reasoning, especially when dealing with borderline values. It takes in account all variables and the combinatorial outputs and bases its decision on the criteria that are met. Table I shows a sample of the different combinations of the fuzzy logic (a total of 81 combinations).

TABLE I DIFFERENT COMBINATION OF FUZZY LOGIC

\begin{tabular}{|c|c|c|c|c|}
\hline \multicolumn{4}{|c|}{ Inputs } & Output \\
\hline Force & Accel. & Gyro & Speed & $\mathrm{CI}$ \\
\hline $\mathrm{L}$ & $\mathrm{L}$ & $\mathrm{H}$ & $\mathrm{M}$ & $\mathrm{M}$ \\
\hline $\mathrm{L}$ & $\mathrm{H}$ & $\mathrm{M}$ & $\mathrm{H}$ & $\mathrm{H}$ \\
\hline$M$ & $\mathrm{~L}$ & $\mathrm{H}$ & $\mathrm{L}$ & $\mathrm{L}$ \\
\hline$M$ & $\mathrm{H}$ & $\mathrm{H}$ & $\mathrm{H}$ & $\mathrm{H}$ \\
\hline $\mathrm{H}$ & $\mathrm{L}$ & $\mathrm{H}$ & $\mathrm{L}$ & $\mathrm{M}$ \\
\hline $\mathrm{H}$ & $\mathrm{H}$ & $\mathrm{L}$ & $\mathrm{M}$ & $\mathrm{H}$ \\
\hline
\end{tabular}

As shown in Table I CI shows the collision index which defines the outputs depending upon the inputs from sensors. 


\section{RESULTS}

GPS Result-

LAT=19.132963 LON=72.939392 SAT=8 PREC=99 CHARS=276205 SENTENCES=1207 CSTM ERR=0 LAT=19.132963 LON=72.939392 SAT=8 PREC=99 CHARS=276684 SENTENCES=1209 CSTM ERR=0

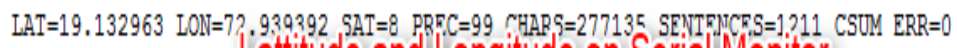

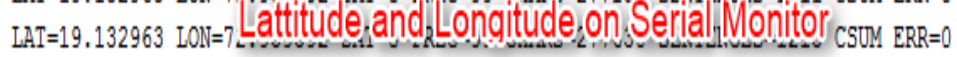
LAT=19.132963 LON=72.939392 SAT=8 PREC=99 CHARS=278177 SENTENCES=1215 CSOM ERR=0 LAT=19.132963 LON=72.939392 SAT=8 PREC=99 CHARS=278667 SENTENCES=1217 CSTM ERR=0 LAT=19.132963 LON=72.939392 SAT=8 PREC=99 CHARS=279105 SENTENCES=1219 CSTM ERR=0 LAT=19.132963 LON=72.939392 SAT=8 PREC=99 CHARS=279599 SENTENCES=1222 CSTM ERR=0 LAT=19.132963 LON=72.939392 SAT=8 PREC=99 CHARS=280058 SENTENCES=1224 CSTM ERR=0 LAT=19.132963 LON=72.939392 SAT=8 PREC=99 CHARS=280517 SENTENCES=1226 CSTM ERR=0 LAT=19.132963 LON=72.939392 SAT=8 PREC=99 CHARS=280976 SENTENCES=1228 CSTM ERR=0 LAI=19.132963 LON=72.939392 SAI=8 PREC=99 CHARS=281435 SENTENCES=1230 CSOM ERR=0 LAI =19.132963 LON=72.939392 SAI=8 PREC=99 CHARS=281894 SENTEICES=1232 CSTM ERR=0 LAT $=19.132963$ LON=72.939392 SAT=8 PREC=99 CHARS=282353 SENTEICES=1234 CSTM ERR=0 LAT $=19.132963$ LON=72.939392 SAT=8 PREC=99 CHARS=282812 SENTENCES=1236 CSTM ERR=0
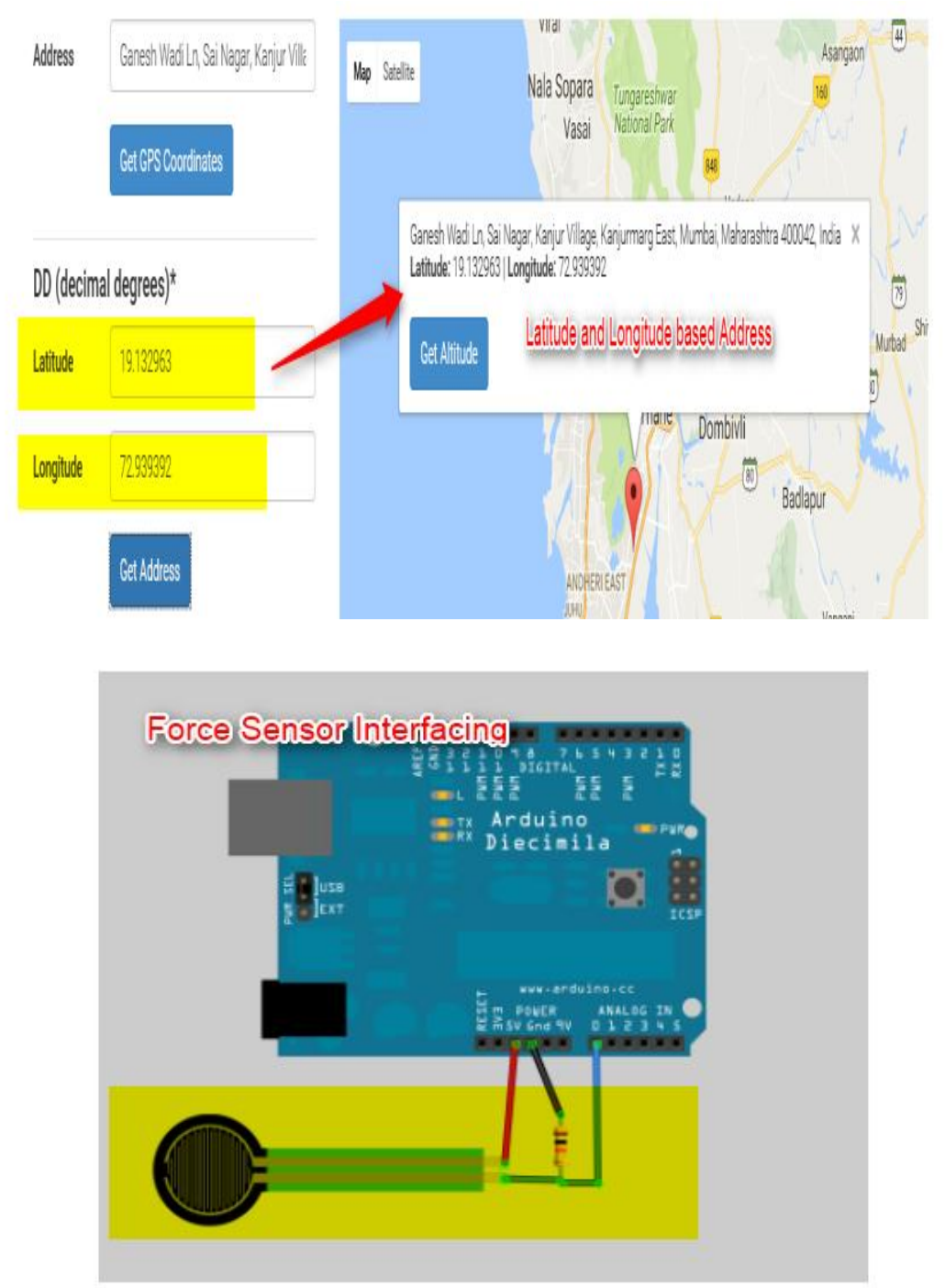


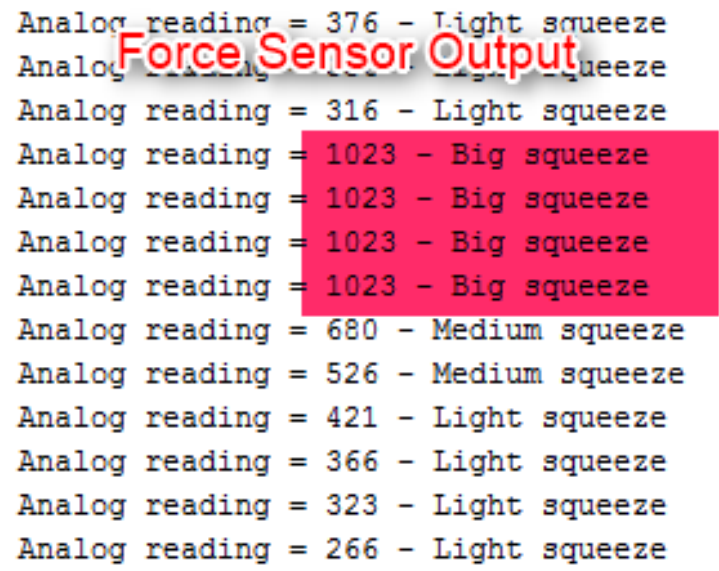

FORCE SENSOR RESULT

\section{CONCLUSION}

This paper presents ADIS system which is capable of informing to the authorities for help. Because of the system mainly the help is provided to the people those are in emergency. The automated notification allows authorities to take faster action as early as possible and to prevent damage, both human and economic.

Moving forward system from prototyping it will be possible to optimize the performance and should be more compact which will be fit into small vehicle also.

\section{ACKNOWLEDGMENT}

It gives us great pleasure in presenting the paper on Accident Detection by an Intelligent System. We would like to take this opportunity to thank our internal guide Prof. S. R. Pandit for giving us all the help and guidance we needed. We are really grateful to him for his kind support. His valuable suggestions were very helpful. We are also grateful to Prof. R. L. Paikrao, Head of Computer Engineering Department, AVCOE, Sangamner for his indispensable support, suggestions. In the end our special thanks to Dr. M. A. Venkatesh Principal, AVCOE, Sangamner for providing various resources such as laboratory with all needed software platforms, continuous Internet connection for our project.

\section{REFERENCES}

[1] "Statistics - Suraya Foundation." Suraya Foundation. N.p., n.d. Web. 03 June 2013.

[2] Park K. Park's textbook of preventive and social medicine. 22nd ed. Jabalpur: Banarsidas Bhanot; 2013. p. 375-8

[3] Accidental Deaths \& Suicides in India - 2013 [Internet]. New Delhi: National Crime Records Bureau, Ministry of Home Affairs, Government of India; 2014 Jun [cited 2016 Apr 14] p. 318. Available from: http://ncrb.nic.in/StatPublications

[4] Fogue, Manuel. et al., "Prototyping an automatic notification scheme for traffic accidents in vehicular networks," Wireless Days (WD), 2011 IFIP, vol., no., pp.1,5, 10-12 Oct. 2011.

[5] Evanco, William (1996) The impact of rapid incident detection on freeway accident fatalities. Mitretek Systems, Inc., WN96W0000071.

[6] "Enform." Lexus, Toyota. N.p., n.d. Web. 15 June 2014.

[7] Johnston, Casey. "The Pursuit of Connection: The \$120K Lexus App and Car Combo." Ars Technica. N.p., n.d. Web. 15 June 2014.

[8] "Auto Security | Car Safety | Navigation System | OnStar." OnStar. N.p., n.d. Web. 15 June 2014.

[9] "OnStar Reviews." Consumer Affairs. N.p., n.d. Web. 15 June 2014.

[10] Montague, Albert, PH.D. Mobile Wireless Phone with Impact Sensor, Detects Vehicle Accidents/thefts, Transmits Medical Exigencyautomatically Notifies Authorities. Patent US2005/0037730 A1. 17 Feb. 2005. Print.

[11] Gabler, Hampton. "Development of an Automated Crash Notification System: An Undergraduate Research Experience." Cite Seer X Beta. N.p., 18 Oct. 2000. Web.

[12] Bhumakar, S. P. "Intelligent Car System for Accident Prevention Using ARM-7."International Journal of Emerging Technology and Advanced Engineering. N.p., 4 Apr. 2012. Web. 